the sun than the earth. There would scem therefore to be little chance of a rich display this year.

No one can question that the calculations so far as they go are perfectly trustworthy. But is it possible, in dealing with an enormous assemblage of metcors in respect of which our knowledge is admittedly very inadequate, to define either its position, extent or density with great exactness? There is still much of mystery involved in comets and meteors. It is just possible that some development or variation in the system of leonids will bring it prominentiy into view again this year. At any rate, this must be regarded as a quite possible contingency, for it is certain that every feature connected with and influencing the visibility of the meteors cannot have been allowed for. Our historical knowledge of the various attributes of the stream is very rough and incomplete, for the swarn has only made one visible return since meteoric astronomy has been recognised as an interesting and important branch of astronomy.

But, whether or not the mathematical conclusions are justified or falsified by the experiences of next week, every one of us encourages the hope that a plentiful, if not a brilliant, display of meteors will be seen. And astronomers in every part of the world will look for it as a duty. Charts will be grot ready for properly recording the paths; cameras will be put into position and every preparation made to suitably record the display should it put in an appearance. The event is not only magnificent as a spectacie, but it is capable of teaching us some valuable lessons.

The moon will offer some interference this year, as she rises on November I 3 at I Ih. Im., on November I 4 at $12 \mathrm{~h} .8 \mathrm{~m}$. and on November 15 at $13 \mathrm{~h}$. $13 \mathrm{~m}$, but she will be in her last quarter, so that her light will only obliterate the faintest class of meteors. She will, unfortunately, be situated near the sickle of Len. The planet Mars will be placed a few degrees north-west of Regulus. On November I4, at 5 h., the moon and Mars will be in conjunction, the latter being $7 \frac{1}{2}$ degrees north.

If the shower proves strong or feeble it should be attentively watched on the three nights of November 13,14 and 15 , if the weather is sufficiently clear for the purpose. Regular meteoric observers will also endeavour to trace some of its metcors on dates preceding and following those mentioned. It is not certain that the radiant moves like the Perseids, and we require morc data with reference to the duration of the shower. Meteors certainly fall from the Sickle-and they are, presumably, true Leonids-between November 7 and 21 . It will be important, therefore, to determine the exact place of the radiant on every night possible during the fortnight mentioned. This will be difficult this year on dates before the maximum owing to the strong mounlight, but it ought to be easy of attainment for a few dates after the I 5 th, for the moun rapidly wanes and the long nights permit of watches during the eight hours or so from the rising of the radiant at about 1oh. I $5 \mathrm{~m}$. to between 6 and 7 a.m.

The feature to which ordinary observers may usefully direct their attention, should the phenomenon recur under pretty bright aspects, is that relating to the time of maximum display and the number of meteors visible. They should be counted and recorded at, say, five-minute intervals, and registered on forms previously prepared for the purpose. Where several observers combine to effect observations they will, of course, look to different quarters of the sky and be careful to avoid numbering the same objects.

The radiant point at about the time of maximum can be well left to the care of those who have adopted the photographic method. We have already accumulated a large number of ricterminations by the ordinary eye method; we now require more correct values, such as it is hoped the camera will afford us.

There are many showers in the region of Leo which furnish streak-leaving meteors, and no object should be included in counts of Leonids if its direction of flight when carried backwards does not cut through the Sickle. 'i he best of these circinal Leonid showers is at $154^{\circ}+40^{\prime \prime}$ from a point about 17 degrees north of the Lemicl radiant.

While observers are watching for the Leonid display, it often happens that not only are a few bright Leonids seen, but several large meteors appear from minor radiants. It used to be the custom to term the latter "sporadic" meteors, but they belons to well defined systems, the great majority of which have now been ascertained. In all cases where a fine meteor is seen its apparent path on the celestial sphere should be as carefully recorded as the circumstances permit, and the time of apparition noted. If this plan were followed in every case a number of

$$
\text { No. } 1619 \text {, VOL. 63] }
$$

multiple observations of the same meteors would be available for computing their real paths in the atmosphere. It is hoped, therefore, that this important feature of the work will not be neglected during the ensuing observations, for it need occupy little time, and will certainly provide some valuable material for after comparison and discussion. Last year, on the morning of November 15, there was a magnificent meteor many times brighter than Venus, and though it was well seen at five or six of the leading observatories in England, its path position was not particularly recorded at any one of them.

The most probable time for the recurrence of the shower will be on the night following November 14, and a watch should be commenced soon after the radiant has risen. As a rule, not many meteors are discharged from a low radiant; but what is lacking in numbers is often compensated for by appearance. The Leonids seen before midnight are usually very conspicuous, owing to their long paths, dense streaks, and apparently more gradual flights than those which appear at a later hour of the night, when the radiant has attained a fair altitude. For my own part, I certainly entertain the hope that the display will put in appearance on November 14, and that, though its splendour may fall far short of that of some previous returns, it may yet prove gratifying to those who have looked for the shower in vain during the last few years. In any case, it is to be hoped that the atmosphere will be favourable, for much depends upon the state of the sky; and it is important that we should ascertain in what strength the event returns. $\quad$ W. F. DENoins.

\section{THE NOBEL PRIZES FOR SCIENTIFIC DISCOVERY.}

$A$ BRIEF note upon the prizes endowed by the late $\mathrm{Dr}$ Nobel has already been given (p. II). A translation into English of the regulations under which the prizes will be awarded is given in Science, and the essential parts are here stated for the convenience of investigators unable to see a copy of the official document just distributed by the Board of Fducation.

The three corporations awarding the Nobel prizes are:

(I) The Royal Academy of Sciences, at Stockholm. The King is the protector of the Academy, which numbers 100 Swedish and Norwegian members and 75 foreign members. (2) The Swedish Academy, at Stockholm. The King is the protector. The members, exclusively Swedish, are limited to 18 (3) The Carolin Institute of Medicine and Surgery, at Stock. holm. The number of professors is 22 .

The Nobel endowment is based on the will of Dr. Aifred Bernhard Nobel, engineer, drawn up November 27, 1895. The stipulations are as follow: :

"The remainder of the fortune which I shall leave shall be disposed of in the following nanner: The capital, converted into safe investments by the executors of my will, shall constitute a fund the interest of which shall be distributed annually as a reward to those who, in the course of the preceding year, shall have rendered the greatest services to humanity. The sum total shall be divided into five equal portions, assigned as follows :

"(I) To the person having made the most inportant discovery or invention in the department of physical science.

" (2) To the person having made the most important discovery or having produced the greatest improvement in chemistry.

"(3) To the author of the most important discovery in the department of physiology or of medicine.

'(4) To the author having produced the most notable literary work in the sense of idealism.

"(5) To the persun having done the most, or the best, in the work of establishing the brotherhood of nations, for the sup. pression or the reduction of standing armies, as well as for the formation and the proplagation of peace conferences.

"The prizcs will be awarded as follows: For physical science and chemistry, by the Swedish Academy of Sciences for works in physiology or medicine, by the Carolin Institute of Stockholm; tor literature, by the Academy of Stockholm; finally, for the work of peace, by a committee of five members elected by the Norwegrian Stortung. It is my expressed will that nationality shall not be considered, so that the prize may accrue to the most worthy, whether he be a Scandinavian or not." 
Each of the annual prizes established by the will will be awarded at least once in the course of every period of five years, commencing with the year immediately following that in which the Nobel endowment enters on its functions, and the sum total of a prize thus awarded will in no case be less than 60 per cent. of the part of the yearly revenues disposable for the distribution of the prizes; neither can it be divided into more than three prizes at the most.

Immediately after the approval by the King of the statute of endowment, the corporations will designate the stipulated number of representatives, who will assemble at Stockholm and elect the members of the board of administration, who will have the management of the endowment fund at the beginning of the year 1901. The executors of the will will take appropriate measures to terminate the settlement of the succession. The first distribution of prizes for all sections will take place, if pos. sible, in IgoI. From the endowment resources will be deducted : First, a sum of 300,000 crowns $(16,000 l$.) for each section - that is, $1,500,000$ crowns $(80,400 i)$ in all-which, with the interest commencing from January I, I900, will be used to cover, in proportion, the expenses of the organisation of the Nobel institutes in addition to the sum the board of adminis. tration shall judge necessary for the acquisition of a special site destined for the administration of the endowment and including a hall for its meetings.

The right of presenting proposals for prizes belongs to -

(1) Native and foreign members of the Royal Academy of Sciences. (2) Members of the Nobel committees for natural philosophy and chemistry. (3) Professors who have received the Nobel prize of the Academy of Science. (4) Ordinary and extraordinary professors of natural sciences and chemistry in the Universities of Upsala, Lund, Christiania, Copenhagen and Helsingförs, in the Carolin Institute of Medicine and Surgery, the Superior Technical Royal School, as well as to the professors of the same sciences in the Stockholm High School. (5) Incumbents of corresponding chairs of at least six universities or high-schools, which the Academy of Science will select, taking care to divide them suitably between the different countries and their universities. (6) Learned men, to whom the Acadenıy shall judge proper to send an invitation to this effect.

The invitations will be sent every year in the manth of September. Proposals for the prize must be made before February $\mathrm{I}$ of the following year. They will be classified by the Nobel committee and subnitted to the college of professors. The Nobel committee will decide which of the works presented shall be submitted to a special examination. The college of professors will pronounce definitely on the distribution of the prize in the course of the month of October. The vote will be taken in secret; if necessary, the question may be decided by drawing lots.

The right to present candidates for the Nobel prize belongs to the members of the Swedish Academy, the French Academy, and the Spanish Academy, which resemble the Swedish Academy in their organisation and aim ; to the inembers of the literary departments of other acadenies, as well as to the members of literary institutions and societies analogous to academies; to professors of zesthetics, of literature and of history in the universities. This order must be published at least every five years.

\section{ELECTRICAL ENGINEERING AS A TRADE} AND A.S A SCIENCE.

I DO not intend to make this in any sense a report of the progress of our Institution dluring the last or any number of years. I shall not, therefore, give any account of the exceedingly good work done by Colonel Crompton and the active service corps of our Electrical Engineer Volunteers in South Africa. I shall not describe how we fited our American cousins in England and France, or how they ficed us; nor what a wonderful success accompanied all that was attempted by us or by them or by M. Mascart and our French colleagues, although I cannot refrain from bearing my testimony to the great kindness of the Prince of Wales and the IBritish Commission in so generously lending us the British Pavilion for our great reception, and giving us the use of one of its rooms for our office all the time of our visit to P'aris.

My brother has tried to get me to introduce to your notice

1 Inaugural Address, delivered at the Institution of Electrical Engineer: on November 3, by Prof. John Perry, F.R.S., P'resident.

No. [6 69. V OL. 63 ] some novel idleas which have come to us during the last ten years in our business of lighting the city of Galway from a fairly constant water-power, using accumulators with a gas plant stand-by. It has almost come to be a practical idea to produce carbide of calcium in wet seasons and utilise it through the gas engine in dry seasons. I was also tempted to discuss the use of large gas engine plant at central stations : and another of several subjects in which I have been recently engaged has been the magnetic effect produced by systems of electric traction. But I have resisted ternptation and have chosen a subject which seems to me much more important.

Your president's address is followed by no discussion. He is, therefore, privileged, but his very privileges cause him to address you with a greater sense of responsibility; he may say what he pleases, but he must be very sure that he has the best interests of the Institution at heart ; the interests of the Institution as a whole, not the interests merely of a few members, and least of all ought he to think of his own interests. Nevertheless, your president speaks not as an omniscient judge, but rather as a very fallitble, very prejudiced, one-sided man who, because he has devoted himself to one part of the work of this Institution, is certain to be unfair in his comments upen other parts of the work.

Vour past presidents represent in this way all classes of members of this Institution. You have had scientific nen, given some of them to calculation and some to experiment, and some to both ; men who have advanced the study of pure science. You have had practical telegraph men, civil and military; men cunning in land and deep-sca telegraphy and telephony; men cunning in railway sigualling. You have had electrical chemists. You have had manufacturers and users of all kinds of electrical appliances. You have had men who devote themselves to the teaching of electrical engineers, and who fully appreciate the fact that no good teacher ought to be out of practical touch with the profession. And nearly all of your past presidents have invented things which are now in practical use

As each of these men has given you at least one address written from his own peculiar point of view, his prejudices are not likely to have done any harm to members who read the other addresses. I know, therefore, that you are good-naturedly prepared to give me plenty of rope. I can predict the twinkle of amusement in the faces of some of my friends when they learn that I am about to take up a subject on which we have had many debates.

In this address I mean to put before you this simple question : Is electrical engincering to remain a profession or is it to become a trade? Is this Institution to continue to be a socicty for the advancement of knowledge in the applications of scientific principles to electrical industries, or is it to become a mere trades union?

Of course, at the present time the outside public are willing to regard membership of this Institution as a symbol of something more than the membership of a mere trades union. During the early growth of any trarle, even stich a trade as that of the plumber, it was really a profession. And a common trade may sudclenly become a profession, if it suddenly begins to develop, as, for example, stone-masonry of a hundred years ago suddenly developed into civil engineering. Electrical engineer. ing has been developed rapidly, so that in the past it has certainly been a profession and not a trade.

Again, we are an institution of engineers, and the general public are willing to class us with other engineering institutions -for example, the Institution of Civil Engineers. $N_{1} w$ the title M.Inst.C.E. is a professional distinction which represents in civil engineering what F.R.C.S does in surgery, or M.R.C.P. in medicine. We owe a great deal to our association with, and recognition by, the Institution of Civil Engineers; our meetings are held in its rooms; many of our nembers are also its members; our proceedings are modelled on its proceedings.

Now this older Institution, governed by the best thoughts of the best British engineers, has laid it down that its associate members, that important class from which the higher class is mainly fed, shall have passed certain specified examinations in pure and applied science. I am not now suggesting that we ought to adopt this science examination method of adnitting any kind of members to our Institution. I do not believe in the wholesale adoption of methods of working from another society. I am asking you carly in my address io remenuler that this greatest of all professional engineering institutions, governed by practical men full of common sense, knowing the wants of their 